\title{
THE USE OF REFLECTION FOR SPIRITUAL CARE LEARNING IN CLINICAL EDUCATION: A PILOT STUDY
}

\author{
Gisella Anastasia ${ }^{1 *}$, Yoyo Suhoyo ${ }^{2}$, Prattama Santoso Utomo², Doni Widyandana² \\ ${ }^{1}$ Medical Education Unit, Faculty of Medicine and Health Science, Universitas Katolik Indonesia Atma Jaya, Jakarta, Indonesia \\ ${ }^{2}$ Department of Medical Education and Bioethics, Faculty of Medicine, Public Health and Nursing, Universitas Gadjah Mada, \\ Yogyakarta, Indonesia
}

Submitted: 15 June 2020; Final Revision from Author: 31 August 2020; Accepted: 06 October 2020

\begin{abstract}
Background: Indonesian society assume spirituality as an important aspect in life especially in sickness. Spiritual care can restore patients' quality of life by providing them comfort, strength, and compassion. Because lack of education about spiritual care, doctors often feel not fully equipped. Reflection has proven to increase awareness of spiritual care, but the impact of this method still needs further research. This study aims to explore the impact of reflection on student awareness about spiritual care.
\end{abstract}

Methods: This study used Interpretative Phenomenological Analysis with reflective writing and in-depth interview. Nine clinical medical students divided into four groups which was facilitated by clinical teacher. Intervention were three reflective writings interspersed with two small group discussion. The writings were analyzed using Transtheoretical Model to identify behavioral change then content analysis for the transcript to explore the study's impact and the feasibility.

Results: Five students increased their awareness because clinical experience, time-management, writing volume, and reflective thinking. Three students increase faster because learning from peers, engage with patient, and role-model. Two students increase slower because lack understanding of reflection and incorrect facilitators' feedbacks. Two students stable because lack understanding of discussion and low engagement with patient. One student experienced a decrease because lack of task-commitment and interest. One student did not get awareness because difficulty interpreting emotions.

Conclusion: Reflection method can be used to teach spiritual care to clinical medical students by considering several factors that might play a role. Further research with improvement to the method is still needed.

Keywords: Spiritual care; spirituality; reflection; clinical medical student

\section{ABSTRAK}

Latar belakang: Masyarakat Indonesia menganggap agama/spiritualitas berperan penting dalam kehidupan terutama pada saat sakit. Spiritual care dapat meningkatkan kualitas hidup pasien dengan memberikan kasih, kekuatan, dan perhatian namun dokter merasa tidak siap karena kurangnya pendidikan mengenai spiritual care. Refleksi terbukti meningkatkan kesadaran mengenai spiritual care namun dampaknya terhadap pembelajaran spiritual care masih belum jelas. Penelitian ini bertujuan menggali dampak metode refleksi terhadap kesadaran mahasiswa mengenai spiritual care.

Metode: Penelitian ini menggunakan Interpretative Phenomenological Analysis dengan tulisan refleksi dan indepth interview. Sembilan Mahasiswa kedokteran tingkat klinik dibagi dalam 4 kelompok yang masing-masing difasilitasi oleh satu dosen klinik. Intervensi berupa tiga tulisan refleksi diselingi dengan dua diskusi kelompok

*corresponding author, contact: gisella.gisella@atmajaya.ac.id 
kecil. Analisis tulisan refleksi menggunakan Transtheoretical Model (TTM) untuk menilai perubahan tingkah laku dan content analysis wawancara untuk menggali dampak dan keterlaksanaan metode tersebut.

Hasil: Lima mahasiswa mengalami peningkatan perilaku karena faktor pengalaman klinik, pemikiran reflektif, manajemen waktu, dan volume tulisan. Tiga mahasiswa mengalami peningkatan lebih cepat karena faktor belajar dari teman, keterkaitan emosi dengan pasien, dan role-model. Dua mahasiswa meningkat lebih lambat karena pemahaman refleksi yang kurang dan umpan balik fasilitator yang salah. Dua mahasiswa stabil karena pemahaman refleksi dan diskusi yang kurang juga kurangnya keterkaitan emosi. Satu mahasiswa mengalami penurunan karena kurangnya task-commitment dan minat. Satu mahasiswa tidak mendapatkan kesadaran karena kesulitan interpretasi emosi pasien. Hambatan dalam pelaksanaan adalah kesibukan dan keterbatasan kasus.

Kesimpulan: Metode refleksi dapat digunakan untuk mengajarkan spiritual care kepada mahasiswa kedokteran klinik dengan memperhatikan beberapa faktor yang mungkin berperan. Penelitian lebih lanjut dengan perbaikan pada metode refleksi masih diperlukan.

Kata kunci: Spiritual care; spiritualitas; refleksi; mahasiswa kedokteran tingkat klinik

\section{PRACTICE POINTS}

- Pengetahuan mahasiswa kedokteran klinik mengenai spiritual care masih rendah.

- Refleksi dapat digunakan sebagai metode pengajaran spiritual care di pendidikan klinik.

- Terdapat beberapa faktor pendukung dan penghambat yang mempengaruhi pelaksanaan metode refleksi dalam pembelajaran spiritual care.

\section{PENDAHULUAN}

Spiritual telah dianggap sebagai salah satu aspek kesehatan manusia oleh WHO. ${ }^{1}$ Pernyataan tersebut menarik banyak penelitian tentang pengembangan spiritual care dalam pelayanan kesehatan menyeluruh., ${ }^{2,3}$ Spiritual care merupakan pelayanan kepada pasien yang sedang mengalami masalah spiritual ${ }^{4}$ dengan memberikan kasih, ${ }^{3,5-7}$ kepercayaan dan empati, ${ }^{8,9}$ harapan, ${ }^{5}$ dan perhatian penuh. ${ }^{6}$ Banyak penelitian menyatakan manfaat spiritual care bagi pasien seperti meningkatkan kualitas hidup pasien dengan meningkatkan kesejahteraan fungsi, ${ }^{10}$ kesejahteraan emosi, ${ }^{10}$ mengurangi kecemasan, ${ }^{4,10}$ dan depresi. ${ }^{4}$

Spiritual care sebaiknya dilakukan oleh suatu tim tenaga kesehatan termasuk dokter dengan pembagian peran yang jelas., ${ }^{2,36}$ Peran dokter adalah peka terhadap masalah spiritual ${ }^{6}$ dan memberikan spiritual care yang sesuai. ${ }^{3,4,11}$ Spiritual care dapat diberikan dengan tindakan sederhana seperti mendengarkan, ${ }^{3,5,11}$ memberikan perhatian penuh, ${ }^{6}$ atau bisa juga membutuhkan tindakan kompleks yang harus melibatkan konselor spiritual yang lebih ahli dalam hal ini. ${ }^{2,6}$

Masyarakat Indonesia menganggap agama memegang peranan penting dalam kehidupan mereka terutama saat mereka menderita penyakit. ${ }^{12}$ Sebagian pasien di Indonesia menyinggung masalah spiritual dan agama saat berkonsultasi dengan dokter. ${ }^{13}$ Standar Kompetensi Dokter Indonesia (SKDI) pun menyatakan mahasiswa kedokteran harus mampu melaksanakan praktik kedokteran yang profesional sesuai dengan nilai dan prinsip Ketuhanan dan mampu menunjukkan kepekaan terhadap aspek biopsikososiokultural dan spiritual pasien dan keluarga ${ }^{14}$ Meskipun demikian, spiritual care dan masalah spiritual belum dimasukkan dalam standar kompetensi. Kesenjangan ini menjadi suatu tantangan dalam implementasi spiritual care pada pendidikan kedokteran Indonesia ditambah dengan kurangnya pelatihan mengenai spiritual care. ${ }^{13,15}$ 
Pada pembelajaran spiritual care, interaksi langsung dengan pasien dan keluarganya memegang peranan penting $^{16}$ oleh karena itu pembelajaran di tingkat klinik dapat dijadikan salah satu cara bersama dengan refleksi yang menggunakan pengalaman interaksi sebagai dasar pembelajaran. ${ }^{17}$ Refleksi terbukti dapat meningkatkan pengetahuan mengenai spiritual care, ${ }^{18,19}$ meningkatkan kemauan, dan kemampuan dalam menciptakan strategi yang tepat dalam melakukan spiritual care ${ }^{19}$ namun dampak tersebut masih memerlukan penelitian lebih lanjut. ${ }^{19}$ Penelitian ini bertujuan menggali dampak metode refleksi terfasilitasi dalam kelompok kecil bagi kesadaran mahasiswa mengenai spiritual care.

\section{METODE}

Penelitian ini menggunakan pendekatan interpretative phenomenological analysis ${ }^{20}$ untuk menggali perspektif mahasiswa kedokteran tingkat klinik di Universitas Katolik Indonesia (Unika) Atma Jaya, Jakarta, Indonesia mengenai dampak dan keterlaksanaan metode refleksi terfasilitasi dalam kelompok kecil terhadap kesadaran mereka mengenai spiritual care. Penelitian menggunakan tulisan refleksi dan semistructured in-depth interview yang berlangsung dari bulan Agustus 2019 sampai Januari 2020. Penelitian ini telah mendapat ethical clearance dari Komisi Etika Penelitian Fakultas Kedokteran Unika Atma Jaya (EC No: 32/07/KEP-FKUAJ/2019).

\section{Sampling}

Convenience sampling digunakan dengan kriteria partisipan adalah mahasiswa kedokteran tingkat klinik yang menjalani pendidikan klinik di Rumah Sakit A; memiliki pengalaman berinteraksi dengan pasien dengan masalah spiritual atau agama yang ditunjukkan dengan menyatakan perhatian pada arti hidup atau mati, Tuhan, dan kepercayaan; mempertanyakan implikasi moral dari pengobatan; menyatakan gangguan tidur; menyatakan adanya konflik batin; dan memperlihatkan beberapa ekspresi seperti kecemasan, menangis, dan marah ${ }^{21}$; dan belum pernah mendapatkan pelatihan atau pendidikan mengenai spiritual care. Terdapat 12 mahasiswa yang menandatangani informed consent dan bersedia mengikuti penelitian.

\section{Tahap persiapan}

Dua belas mahasiswa terbagi menjadi 4 kelompok dan tiap kelompok difasilitasi oleh satu dosen klinis. Setiap dosen klinis diberikan kuliah interaktif "Praktik spiritual care" dan kuliah interaktif "Fasilitasi refleksi dalam diskusi kelompok kecil”. Seluruh partisipan diberikan kuliah interaktif "Membuat tulisan refleksi”. Partisipan diberikan panduan pertanyaan refleksi, dan 3 sumber bacaan softcopy mengenai spiritual care. Partisipan pun diminta untuk menandatangani informed consent dan survey demografik.

\section{Tahap pelaksanaan}

Metode pelaksanaan refleksi terdiri dari tiga tulisan refleksi dan dua diskusi kelompok kecil. Tulisan refleksi dibuat berdasarkan Model Gibbs ${ }^{22}$ dengan batasan jumlah 500 kata. Dalam pelaksanaan, batasan jumlah kata dihapus karena dianggap kurang dan menghambat dalam penulisan. Dasar tulisan refleksi adalah pengalaman mahasiswa dalam berinteraksi langsung dengan pasien yang mengalami masalah spiritual. Tulisan kedua dan ketiga harus mengambil kasus baru setelah diskusi dilakukan. Pada diskusi kelompok kecil mahasiswa berbagi pengalaman refleksi mereka, berdiskusi, dan mendapatkan umpan balik dari teman dan fasilitator. Diskusi terfasilitasi tersebut membantu mahasiswa dalam mengarahkan dan mengidentifikasi persepsi, membuat rencana di masa depan, dan belajar dari pengalaman orang lain ${ }^{23,24}$ sehingga membantu proses refleksi. Diskusi kelompok setelah tulisan refleksi ketiga tidak dilakukan karena pengukuran dilakukan menggunakan tulisan refleksi. Pada awal perencanaan interval waktu tiap kegiatan adalah 1 minggu namun dalam pelaksanaan terdapat keterlambatan selama 3 minggu akibat mahasiswa terlambat mengumpulkan tulisan refleksi. Keterlambatan ini tidak mempengaruhi hasil penelitian. 


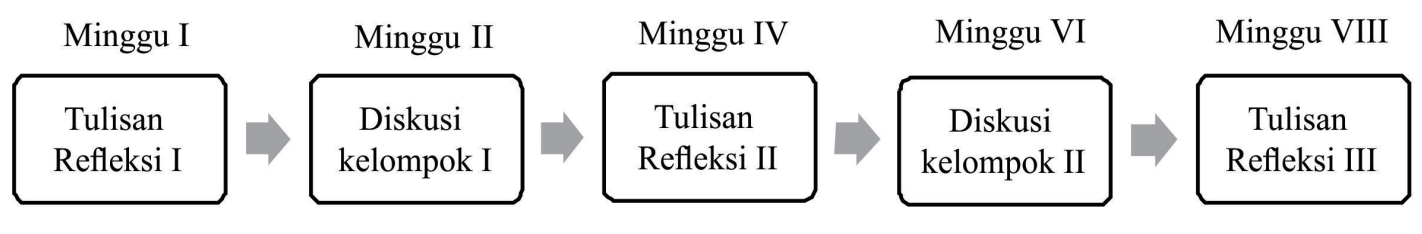

Gambar 1. Metode Pelaksanaan Refleksi

\section{Pengumpulan data}

Tiga tulisan refleksi dikumpulkan melalui email dan wawancara dilakukan setelah hasil tulisan refleksi dianalisis kepada seluruh partisipan. Semi-structured in-depth interview dilakukan melalui tatap muka dan telepon. Peneliti sebagai moderator $(G)$ dibantu oleh satu asisten peneliti (E) dalam merekam wawancara dengan rekorder. Hasil rekam wawancara ditranskrip secara verbatim oleh dua asisten peneliti (E, S).

\section{Analisis data}

Tulisan refleksi dianalisis oleh dua peneliti $(G, P)$ menggunakan thematic analysis berdasarkan 5 tahap transtheoretical model (TTM) yang dibuat oleh Ledford et al. untuk mengidentifikasi perubahan tingkah laku dalam berhadapan dengan pasien masalah spiritual $^{19}$ terutama tahap evaluasi dan analisis siklus Gibbs sampai terjadi kesepakatan. Saat terjadi ketidaksepakatan, pihak ketiga diminta untuk memberikan pendapat (Ri, Ra).

Analisis konten $^{25}$ dari transkrip wawancara dilakukan oleh 2 peneliti $(G, P)$. Peneliti pertama $(G)$ mengkoding transkrip wawancara dan membentuk tema perjalanan pembelajaran kemudian peneliti kedua (P) mereview koding dan tema tersebut sampai terjadi kesepakatan. Peneliti kemudian melakukan proses compare dan contrast dari perkembangan perilaku dan perjalanan pembelajaran mahasiswa untuk mendapatkan dampak dan faktor yang berperan. Peneliti melakukan member checking dengan mengembalikan hasil analisis kepada setiap partisipan dan meminta persetujuan mereka.

\section{HASIL DAN PEMBAHASAN}

Dua dari 12 partisipan mengundurkan diri di awal tahap pelaksanaan karena tidak dapat membagi waktu dengan kesibukan pendidikan klinik dan satu partisipan drop out karena tidak mengumpulkan tulisan refleksi kedua sehingga partisipan akhir berjumlah 9 mahasiswa. Jumlah tersebut sudah sesuai dengan pendekatan interpretative phenomenological analysis $^{20}$ dan hasil wawancara mencapai jenuh pada wawancara mahasiswa kesembilan.

\section{Karakteristik partisipan}

Hasil karakteristik partisipan cukup homogen pada karakter IPK, ras/suku, pengalaman spiritual, persepsi taat beragama, dan aktif dalam keagamaan.

Tabel 1. Karakteristik Partisipan Penelitian

\begin{tabular}{|c|c|}
\hline Karakteristik & $\begin{array}{c}\text { Jumlah } \\
\text { Mahasiswa }\end{array}$ \\
\hline $\begin{array}{l}\text { Jenis Kelamin } \\
\text { Laki-Laki } \\
\text { Perempuan }\end{array}$ & $\begin{array}{l}4 \\
5\end{array}$ \\
\hline $\begin{array}{l}\text { Tingkatan } \\
\text { Tahun Pertama } \\
\text { Tahun Kedua }\end{array}$ & $\begin{array}{l}6 \\
3\end{array}$ \\
\hline $\begin{array}{l}\text { Agama } \\
\text { Katolik } \\
\text { Protestan }\end{array}$ & $\begin{array}{l}4 \\
5\end{array}$ \\
\hline $\begin{array}{l}\text { Indeks Prestasi } \\
\text { Tinggi (IPK > 3.3) } \\
\text { Sedang (IPK 2.7-3.3) }\end{array}$ & $\begin{array}{l}2 \\
7\end{array}$ \\
\hline $\begin{array}{l}\text { Ras/Suku } \\
\text { Tionghoa } \\
\text { Batak }\end{array}$ & $\begin{array}{l}7 \\
2\end{array}$ \\
\hline $\begin{array}{l}\text { Sosioekonomi } \\
\text { Tinggi (> Rp } 10 \text { juta) } \\
\text { Sedang (Rp } 5 \text { juta-Rp } 10 \text { juta) }\end{array}$ & $\begin{array}{l}5 \\
4\end{array}$ \\
\hline $\begin{array}{l}\text { Pelatihan cara refleksi } \\
\text { Sudah pernah } \\
\text { Belum pernah }\end{array}$ & $\begin{array}{l}5 \\
4\end{array}$ \\
\hline $\begin{array}{l}\text { Persepsi kemampuan menilai diri } \\
\text { sendiri } \\
\text { Baik } \\
\text { Tidak baik }\end{array}$ & $\begin{array}{l}5 \\
4\end{array}$ \\
\hline
\end{tabular}




\section{Karakteristik}

Pengalaman spiritual

Sudah pernah

Belum pernah

Anggapan sebagai diri yang taat

beragama.

Taat

Tidak taat

Keaktifan dalam kegiatan keagamaan.

Aktif

Tidak aktif
Jumlah

Mahasiswa

7

7

2

7

2

Perkembangan perilaku spiritual care mahasiswa

Pada hasil analisis tulisan refleksi didapatkan 3 mahasiswa yang mengalami peningkatan perilaku di refleksi kedua, 2 mahasiswa mengalami peningkatan di refleksi ketiga, 2 mahasiswa tidak mengalami peningkatan, satu mahasiswa mengalami penurunan di refleksi ketiga, dan satu mahasiswa tidak mendapatkan kesadaran.

Tabel 2. Perkembangan Perilaku Spiritual Care Mahasiswa

\begin{tabular}{cccc}
\multirow{2}{*}{ Kode Subjek } & \multicolumn{2}{c}{ Perkembangan Perilaku Spiritual Care Mahasiswa } \\
\cline { 2 - 3 } & Refleksi I & Refleksi II & Refleksi III
\end{tabular}

Mahasiswa yang mengalami peningkatan pada refleksi kedua

$\begin{array}{clll}\text { A } & \text { Precontemplation } & \text { Action } & \text { Action } \\ \text { RY } & \text { Contemplation } & \text { Action } & \text { Action } \\ \text { V } & \text { Precontemplation } & \text { Contemplation } & \text { Contemplation }\end{array}$

Mahasiswa yang mengalami peningkatan pada refleksi ketiga

$\begin{array}{llll}\mathrm{R} & \text { Precontemplation } & \text { Precontemplation } & \text { Action } \\ \mathrm{H} & \text { Contemplation } & \text { Precontemplation } & \text { Preparation }\end{array}$

Mahasiswa yang tidak mengalami peningkatan

$\begin{array}{llll}\text { M } & \text { Contemplation } & \text { Precontemplation } & \text { Contemplation } \\ \mathrm{Y} & \text { Contemplation } & \text { Precontemplation } & \text { Contemplation }\end{array}$

Mahasiswa yang mengalami penurunan pada refleksi ketiga
$\mathrm{S}$
Contemplation
Contemplation
Precontemplation

Mahasiswa yang tidak mengalami perubahan dalam refleksi ST Precontemplation Precontemplation

Precontemplation

Peningkatan dan penurunan perilaku tersebut dipengaruhi oleh beberapa faktor. Faktor ini ditemukan berdasarkan perjalanan pembelajaran mahasiswa dari hasil analisis wawancara dengan penjelasan urutan dari penekanan mahasiswa dalam kelompok tersebut sebagai berikut:

\section{Mahasiswa yang mengalami peningkatan perilaku}

Pada mahasiswa yang mengalami peningkatan perilaku mengenai spiritual care ditemukan beberapa faktor yang mempengaruhi. Tiga mahasiswa mengalami peningkatan perilaku lebih cepat pada refleksi kedua dikarenakan faktor pertama yaitu mereka tidak hanya belajar dari umpan balik fasilitator tetapi juga dari teman. Dengan berdiskusi bersama teman dan fasilitator maka mereka dapat belajar dari sudut pandang yang lebih banyak dan beragam $^{26,27}$ sehingga membantu mereka dalam membentuk suatu pemikiran baru, dan membuat rencana di masa depan. ${ }^{26,27}$ 
"Kalau berdua dan temennya aktif jadi bisa dapat sisi lain misalnya cara pandangnya dia terhadap kasus aku seperti apa, yang mungkin awalnya aku tidak sadar. Kalau sendirian hanya dari sudut pandang aku dan fasilitator meng-affirmative saja sehingga kurang dapat sisi lainnya." (RY,4,30-37)

Faktor kedua adalah pengalaman klinik mahasiswa tahun kedua yang seluruhnya mengalami peningkatan. Mahasiswa yang lebih senior memiliki lebih banyak pengalaman klinik yang merupakan suatu pemicu untuk seseorang melakukan refleksi sehingga semakin sering seseorang terpapar maka semakin sering ia berefleksi dan kemampuan refleksinya akan berkembang. ${ }^{28}$ Faktor ketiga adalah faktor keterkaitan emosi (engage) dengan pasien membantu mahasiswa dalam berefleksi. Mahasiswa yang memiliki keterkaitan emosi dengan pasiennya mengalami peningkatan lebih cepat ke tahap yang lebih tinggi. Dalam berefleksi, kita menghadirkan perasaan termasuk emosi untuk dievaluasi. ${ }^{17}$ Maka dari itu, semakin dalam emosi yang terkait dengan kasus pasien maka refleksi akan semakin dalam. ${ }^{27}$ Selain itu, proses analisis dan berpikir akan menjadi semakin kritis. ${ }^{24}$

"Mudah yang kedua karena merasakan sekali dengan pasiennya, jadi lebih mengalir." (A,2,41-43)

Faktor keempat adalah faktor role-model. Mahasiswa yang mendapat contoh praktik nyata spiritual care meningkat lebih cepat karena mempermudah pembelajaran spiritual care yang merupakan hal baru ${ }^{15}$ dan sebagai panduan dalam mengetahui kapan, seperti apa, dan peran mereka dalam spiritual care ${ }^{16}$ dan akan mendorong mereka untuk melakukan spiritual care dalam pelayanan klinisnya. ${ }^{29}$ Faktor kelima yang mempengaruhi adalah manajemen waktu. Mahasiswa yang pintar dalam membagi waktu lebih banyak mengalami peningkatan dikarenakan untuk berefleksi dengan baik, mahasiwa membutuhkan waktu khusus, ${ }^{26}$ sedangkan hal ini sulit dilakukan dalam pendidikan klinik yang penuh dengan kesibukan oleh karena itu mahasiswa yang dapat membagi waktu dengan baik dapat berefleksi lebih baik.
Faktor keenam adalah volume tulisan. Mahasiswa yang menyatakan batasan jumlah kata kurang lebih banyak mengalami peningkatan. Semakin banyak jumlah kata yang dibuat oleh mahasiswa menandakan semakin detail mahasiswa menulis mengenai pengalamannya dan hal tersebut membuat mereka berefleksi lebih dalam ${ }^{30}$ namun hal ini masih memerlukan penelitian lebih lanjut. ${ }^{30}$

"Maksudnya kalau kita mau benar-benar lihat dan analisis, mau refleksi dengan baik, 500 kata menurut aku tidak cukup." (RY,5,4-6)

Faktor terakhir adalah pemikiran reflektif. Mahasiswa laki-laki lebih banyak mengalami peningkatan karena lebih memiliki reflective thinking dibanding perempuan. ${ }^{31}$ Namun, hasil ini bertentangan dengan penelitian lain yang menyatakan jenis kelamin tidak mempengaruhi kemampuan refleksi ${ }^{32}$ sehingga faktor ini perlu diteliti lebih lanjut mengingat kemungkinan tumpang tindih pengaruh dengan pengalaman klinik yaitu 3 dari 4 mahasiswa berjenis kelamin laki-laki merupakan mahasiswa tahun kedua.

Dua mahasiswa baru mengalami peningkatan di refleksi ketiga dikarenakan dua faktor yang menghambat pembelajaran yaitu dari pemahaman mereka mengenai cara refleksi yang masih kurang. Mahasiswa yang tidak memahami cara refleksi dapat terjadi salah persepsi dalam berefleksi ${ }^{26}$ sehingga tidak membentuk pemikiran baru dalam refleksi ${ }^{24}$. Penting bagi institusi pendidikan untuk memperkenalkan metode refleksi dari awal pendidikan kedokteran sehingga mereka dapat mengembangkan keterampilan self-regulation ${ }^{24,27}$ sejak dini agar terbentuk life-long learning. ${ }^{26}$

"Paling bingung tulisnya harus format bagaimana saja." $(H, 1,21)$

Faktor lainnya adalah umpan balik dengan fokus refleksi yang salah dari fasilitator. Umpan balik fasilitator berperan penting membantu mahasiswa dalam mengarahkan fokus refleksi sesuai dengan tujuan pembelajaran ${ }^{26,27}$ dan memberikan arahan dalam membentuk suatu rencana tindakan di masa depan $^{24,33}$ oleh karena itu umpan balik fasilitator 
dengan fokus yang salah dapat membentuk pemikiran mahasiswa dengan fokus yang salah pula.

"Ketika ada pertanyaan, dokternya menjawab tetapi lebih ke arah profesionalisme ... dokternya lebih ke apa yang harus kita lakukan secara profesional, sebagai seorang dokter." (R,2,41-45)

Namun, dengan kegiatan refleksi yang berulang, mahasiswa semakin terbiasa berefleksi sehingga keterampilan refleksi mereka semakin baik seiring dengan waktu. ${ }^{28}$

\section{Mahasiswa yang tidak mengalami perubahan perilaku}

Dua mahasiswa yang tidak mengalami perubahan perilaku terdapat 3 faktor yang mempengaruhi yaitu pada faktor pertama adalah pemahaman mengenai cara refleki yang masih kurang diikuti dengan kurangnya engage dengan pasien dan pemahaman cara diskusi yang masih kurang. Apabila mahasiswa tidak mengetahui cara berdiskusi maka ia akan menjadi pasif dalam berdiskusi sedangkan berperan aktif merupakan salah satu cara untuk meningkatkan pembelajaran. ${ }^{29}$

"Pertamanya sulit karena bingung mau diskusinya bagaimana ... saya bingung cara diskusinya bagaimana." (M,1,13-17)

\section{Mahasiswa yang mengalami penurunan perilaku}

Satu mahasiswa yang mengalami penurunan perilaku di refleksi ketiga dipengaruhi oleh dua faktor. Faktor pertama adalah task-commitment yang kurang. Renzulli ${ }^{34}$ menyebutkan bahwa komitmen terhadap tugas adalah kemampuan untuk tetap tekun dan bertahan pada tugas diluar perasaan tidak mampu, dan faktor kebutuhan menjadi salah satu pendorongnya. ${ }^{35}$ Pada penelitian ini, refleksi tidak dimasukkan ke dalam penilaian dan kurikulum pembelajaran oleh karena itu ada kemungkinan faktor kebutuhan dari pembelajaran spiritual care dirasakan kurang oleh mahasiswa yang berdampak pada rendahnya task commitment.
"Tapi kadang-kadang bingung cari pasien, terus ya sudah daripada tidak ada pasien, ke ambil yang kirakira, lumayan bingung jadi masalahnya apa, bingung gitu." (S,1,4-7)

Faktor kedua adalah minat mahasiswa yang kurang. Mahasiswa merasa terbebani menyatakan kurangnya kemauan dan niat untuk melakukan refleksi sedangkan refleksi merupakan proses self-regulated ${ }^{27}$ sehingga perlu adanya niat dari diri sendiri untuk melakukan refleksi agar proses refleksi berjalan dengan baik. ${ }^{24}$

"Refleksinya mungkin tidak perlu sampai 3 kali karena buat 1 saja susah belum ada tugas refleksi dari dr. L dan temen-temen lain juga tidak buat jadinya seperti dikejar-kejar terus.” (S,3,29-33)

\section{Mahasiswa yang tidak mengalami perubahan}

Satu mahasiswa yang tidak mengalami perubahan dalam refleksi dipengaruhi oleh berbagai faktor. Pertama adalah kesulitan interpretasi emosi. Proses refleksi membutuhkan keterkaitan emosi dan seseorang menyatakan emosi yang ia rasakan untuk dievaluasi ${ }^{17}$ sehingga semakin dalam emosi yang terkait dengan kasus pasien maka refleksi akan semakin dalam. ${ }^{27}$ Keterkaitan emosi juga diperlukan dalam tindakan spiritual care dan empati ${ }^{9}$ merupakan salah satu komponennya. Dalam berempati, mahasiswa harus mampu untuk merasakan dan melihat dari sudut pandang pasien ${ }^{36}$ sehingga apabila mahasiswa kesulitan untuk menginterpretasikan emosi maka ia akan kesulitan dalam memahami perasaan pasien dan berempati. Adanya mahasiswa kedokteran tingkat klinik yang masih kesulitan dalam menginterpretasikan emosi pasiennya merupakan suatu peringatan bagi institusi pendidikan untuk memperhatikan pengajaran mengenai empati pada mahasiswa kedokteran mengingat pentingnya empati dalam profesionalitas seorang dokter. ${ }^{37}$

"Kesulitan untuk menggambarkan emosional dari orang lain, menginterpretasikan contohnya pada saat kejadian itu seperti apa emosi pasien atau emosi keluarga pasien, itu yang saya bingung, saya bingung antara kesal, marah atau sedih." (ST,1,14-18;20-26) 
Faktor kedua adalah minat mahasiswa yang kurang diikuti dengan tidak adanya role-model dan umpan balik fasilitator dengan arahan yang salah.

\section{Keterlaksanaan metode refleksi dalam pembelajaran spiritual care}

Dari segi keterlaksanaan metode refleksi untuk pembelajaran spiritual care, mahasiswa mengalami beberapa hambatan yaitu kendala waktu. Kesibukan mahasiswa di pendidikan klinik ${ }^{38}$ yang diperparah dengan waktu penelitian yang cukup panjang menjadi suatu hambatan besar. Hambatan lain adalah kurangnya kasus dan kontak dengan pasien yang mengalami masalah spiritual. Interaksi mahasiswa dengan pasien dan keluarganya merupakan suatu komponen penting dalam pembelajaran spiritual care ${ }^{16}$ oleh karena itu kurangnya kasus dan kontak menjadi hambatan bagi mahasiswa dalam pembelajaran. Kedua hal ini sangat berhubungan dengan stase klinik. Walaupun 50\% pasien di Indonesia menyatakan masalah spiritual mereka kepada dokter, ${ }^{13}$ namun pasien dengan penyakit berat lebih menyatakan masalah spiritual mereka ${ }^{39}$ oleh karena itu kasus spiritual lebih ditemukan pada stase klinik karena lebih banyak pasien yang menderita penyakit yang mengancam jiwa. ${ }^{39}$

"Saat di Kulit saya susah mencari bahan, karena tidak ada masalah spiritual kecuali pasien yang di rawat sedangkan saat saya bedah atau obsgyn lebih banyak ketemu." (M,3,23-28)

Hambatan terakhir adalah pemahaman mahasiswa mengenai spiritual care yang masih kurang. Mengingat dalam berefleksi, pembelajaran terjadi saat mahasiswa membandingkan pengalaman baru dengan pengetahuan yang ada (existing knowledge ${ }^{27}$ maka sebaiknya diberikan pelatihan spiritual care bagi mahasiswa sebelum penelitian. sehingga mereka kesulitan berefleksi.

"Sulitnya dalam pemahaman spiritualitasnya itu secara umum itu apa, spiritual dalam hal apa, menghubungkan spiritual, spiritualisme ini ke kasuskasus yang saya hadapi." (V,1,16-21)

Berdasarkan hasil tersebut maka dibuat skema konsep pembelajaran spiritual care mahasiswa klinik menggunakan metode refleksi.

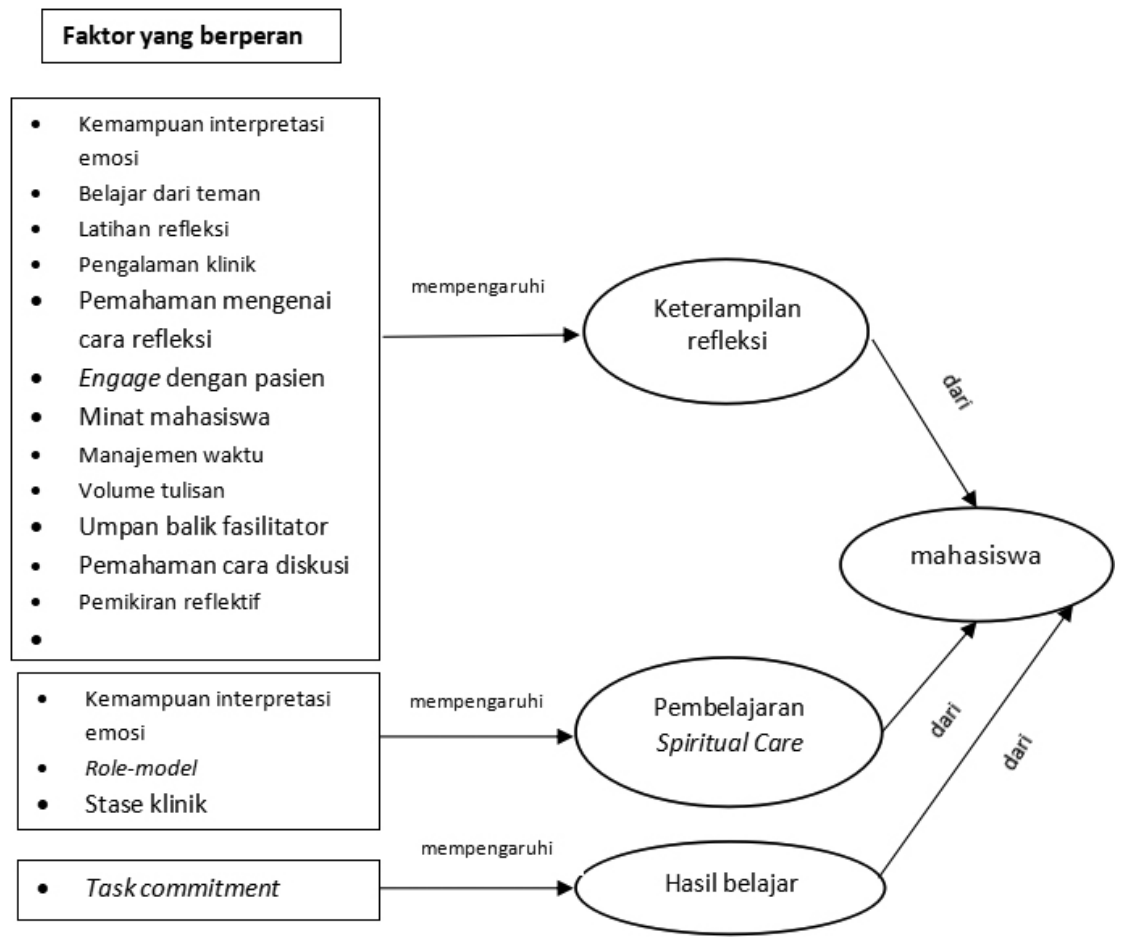

Gambar 2. Skema Konsep Pembelajaran Spiritual Care mahasiswa tingkat klinik menggunakan metode refleksi 


\section{Rancangan penelitian di masa depan}

Melihat berbagai faktor yang mempengaruhi metode refleksi maka peneliti menyusun suatu rancangan pembelajaran yang dapat diadaptasi oleh berbagai konteks penelitian dan juga profesi dalam pembelajaran spiritual care menggunakan metode refleksi. Pertama, memasukkan spiritual care ke dalam kurikulum pembelajaran klinik atau melakukan kerjasama dengan beberapa departemen klinik untuk meningkatkan minat dan mempermudah penjadwalan. Kedua, Memberikan pelatihan spiritual care kepada seluruh dosen klinik dengan penilaian di akhir pelatihan agar dosen klinik dapat mengaplikasikannya dalam pelayanan klinis dan menjadi role-model. Ketiga, memberikan pelatihan cara fasilitasi diskusi refleksi untuk fasilitator agar mereka dapat memfasilitasi jalannya diskusi refleksi. Keempat, memberikan pelatihan spiritual care kepada partisipan untuk meningkatkan existing knowledge mereka mengenai spiritual care. Kelima, memberikan pelatihan cara refleksi dan diskusi kepada partisipan dengan tujuan agar partisipan dapat membuat tulisan refleksi diikuti dengan evaluasi di akhir pelatihan. Keenam, Refleksi dilakukan per departemen klinik untuk mempermudah pengaturan jadwal dan frekuensi refleksi. Ketujuh, Pada departemen minor sebaiknya tulisan refleksi dilakukan hanya dua kali dengan jeda dua minggu untuk menyediakan waktu bagi mahasiswa untuk berefleksi dan kontak dengan pasiennya. Kedelapan, menaikkan batasan jumlah kata menjadi 500-750 kata untuk memberikan kebebasan bagi mahasiswa untuk berefleksi namun juga memperhatikan waktu bagi fasilitator untuk menilai refleksi mahasiswa.

\section{Kekuatan dan keterbatasan penelitian}

Penelitian ini memberikan penjelasan mendalam mengenai dampak metode refleksi terhadap kesadaran mahasiswa disertai dengan faktor yang mungkin berperan dan juga hambatan yang ditemui selama pelaksanaan. Hal ini membantu dalam pengembangan metode refleksi di masa depan untuk pembelajaran spiritual care di tingkat klinik yang belum pernah diteliti sebelumnya.

Limitasi dalam penelitian ini adalah jumlah sampel yang belum cukup untuk melakukan analisis kuantitatif. Walapun terdapat penelitian yang menggunakan perhitungan kuantitatif dengan jumlah yang sedikit $(\mathrm{N}=9),{ }^{40}$ penambahan jumlah sampel dapat dipertimbangkan. Kedua, setting penelitian yang dilakukan di satu rumah sakit dan semua partisipan berasal dari satu unversitas membuat data dari penelitian mungkin tidak dapat digeneralisasikan untuk setting yang berbeda. Penelitian lebih lanjut mengenai dampak dari metode pelaksanaan refleksi ini pada setting lain perlu dilakukan untuk memperkuat hasil dari penelitian. Ketiga, bias dari peneliti sebagai moderator wawancara mungkin mempengaruhi jalannya proses wawancara dengan partisipan. Peneliti mencoba meminimalisir bias dengan menggunakan panduan pertanyaan yang telah dibuat dan direview sebelumnya. Memakai moderator dari luar penelitian pun dapat menjadi suatu pilihan untuk menghindari bias tersebut.

\section{KESIMPULAN}

Metode refleksi dapat digunakan untuk mengajarkan spiritual care kepada mahasiswa kedokteran tingkat klinik dengan mempertimbangkan beberapa faktor pendukung. Faktor-faktor tersebut antara lain adanya diskusi bersama fasilitator dan teman, adanya latihan refleksi bagi mahasiswa, keterkaitan emosi dengan pasien digali, contoh praktik dari role-model, penjadwalan yang baik, dan adanya kebebasan dalam menulis refleksi. Faktoryang masih menjaditantangan adalah kurangnya kemampuan interpretasi emosi, kurangnya task-commitment mahasiswa, pemahaman mahasiswa mengenai cara refleksi dan diskusi yang kurang, kurangnya keterkaitan emosi dengan pasien, minat mahasiswa yang rendah, kurangnya role-model, pengaturan frekuensi refleksi tidak sesuai stase klinik, dan tidak adanya pembekalan spiritual care bagi mahasiswa.

\section{SARAN}

Praktisi yang akan menggunakan metode refleksi dalam pengajaran spiritual care sebaiknya memperhatikan pengetahuan mahasiswa mengenai refleksi dan spiritual care disamping penjadwalan yang baik. Penelitian lebih lanjut dengan melakukan perbaikan pada metode pelaksanaan refleksi perlu 
dilakukan untuk menggali kembali pengaruhnya terhadap kesadaran mahasiswa.

\section{UCAPAN TERIMA KASIH}

Penulis mengucapkan terima kasih kepada dr. Rachmadya Nur Hidayah, M.Sc, Ph.D dan Rilani Riskiyana, S.Kep.,Ns., M.Med.Ed dalam memberikan pendapat atas ketidaksepakatan dalam analisis tulisan refleksi. Penulis juga ingin mengucapkan terima kasih kepada Erni dan Sandy sebagai asisten peneliti yang membantu jalannya penelitian sampai dalam transkrip wawancara dan juga seluruh fasilitator dan partisipan yang bersedia meluangkan waktunya untuk mengikuti penelitian ini. Penulis juga mengucapkan terima kasih pada FKIK Unika Atma Jaya dalam menanggung seluruh biaya penelitian ini.

\section{DEKLARASI KEPENTINGAN}

Seluruh biaya penelitian ditanggung oleh FKIK Unika Atma Jaya.

Para penulis mendeklarasikan bahwa tidak terdapat konflik kepentingan apapun terkait studi pada naskah ini.

\section{DAFTAR SINGKATAN}

FKIK : Fakultas Kedokteran dan Ilmu Kesehatan UNIKA: Universitas Katolik Indonesia

TTM : Transtheoretical Model

\section{KONTRIBUSI PENULIS}

Gisella Anastasia - perencanaan, pengumpulan data, analisis dan interpretasi data, pelaporan dan revisi manuskrip.

Yoyo Suhoyo - perencanaan, analisis dan interpretasi data, dan review manuskrip.

Prattama Santoso Utomo - analisis dan interpretasi data, review dan revisi manuskrip.

Doni Widyandana - perencanaan dan review manuskrip.

\section{DAFTAR PUSTAKA}

1. WHO executive board. Review of the Constitution of the World Health Organization: report of the Executive Board special group [Internet]. 1998 Jan [cited 2020 Mar 4]. (101st session). Report No.: EB101.R2. Available from: http://apps.who.int/gb/archive/pdf_files/ EB101/pdfangl/angr2.pdf

2. Koenig HG. The Spiritual Care Team: Enabling the Practice of Whole Person Medicine. Religions. 2014 Dec;5(4):1161-74.

3. Puchalski CM, Vitillo R, Hull SK, Reller $\mathrm{N}$. Improving the spiritual dimension of whole person care: reaching national and international consensus. J Palliat Med. 2014 Jun;17(6):642-56.

4. Ichihara K, Ouchi S, Okayama S, Kinoshita F, Miyashita M, Morita T, et al. Effectiveness of spiritual care using spiritual pain assessment sheet for advanced cancer patients: A pilot nonrandomized controlled trial. Palliat Support Care. 2019 Jan 26;1-8.

5. Anandarajah G, Hight E. Spirituality and Medical Practice: Using the HOPE Questions as a Practical Tool for Spiritual Assessment. AFP. 2001 Jan 1;63(1):81.

6. Puchalski CM. The role of spirituality in health care. Proc (Bayl Univ Med Cent). 2001 Oct;14(4):352-7.

7. Selby D, Seccaraccia D, Huth J, Kurrpa K, Fitch M. A Qualitative Analysis of a Healthcare Professional's Understanding and Approach to Management of Spiritual Distress in an Acute Care Setting. Journal of Palliative Medicine. 2016; 19:1197-204.

8. Pronk K. Role of the doctor in relieving spiritual distress at the end of life. Am J Hosp Palliat Care. 2005 Dec;22(6):419-25.

9. Tiew LH, Creedy DK. Development and preliminary validation of a composite Spiritual Care-Giving Scale. Int J Nurs Stud. 2012 Jun;49(6):682-90.

10. Jafari N, Farajzadegan Z, Zamani A, Bahrami F, Emami H, Loghmani A, et al. Spiritual therapy to improve the spiritual well-being of Iranian women with breast cancer: a randomized controlled trial. Evid Based Complement Alternat Med. 2013;2013:353262. 
11. Vermandere M, De Lepeleire J, Smeets L, Hannes K, Van Mechelen W, Warmenhoven $\mathrm{F}$, et al. Spirituality in general practice: a qualitative evidence synthesis. Br J Gen Pract. 2011 Nov;61(592):e749-760.

12. Rochmawati E, Wiechula R, Cameron K. Centrality of spirituality/religion in the culture of palliative care service in Indonesia: An ethnographic study. Nursing \& Health Sciences. 2018;20(2):231-7.

13. Ramakrishnan P, Karimah A, Kuntaman K, Shukla A, Ansari BKM, Rao PH, et al. Religious/ spiritual characteristics of indian and indonesian physicians and their acceptance of spirituality in health care: a cross-cultural comparison. J Relig Health. 2015 Apr;54(2):649-63.

14. Indonesian Medical Council. Standar Kompetensi Dokter Indonesia. Konsil Kedokteran Indonesia. 2012;

15. Lucchetti G, Ramakrishnan P, Karimah A, Oliveira GR, Dias A, Rane A, et al. Spirituality, Religiosity, and Health: a Comparison of Physicians' Attitudes in Brazil, India, and Indonesia. Int J Behav Med. 2016 Feb;23(1):6370.

16. Paal P, Helo Y, Frick E. Spiritual Care Training Provided to Healthcare Professionals: A Systematic Review. J Pastoral Care Counsel. 2015 Mar;69(1):19-30.

17. Boud D, Keogh R, Walker D. Reflection: Turning Experience Into Learning. Kogan Page; 1985. $180 \mathrm{p}$

18. Gordon T, Kelly E, Mitchell D. Spiritual Care for Healthcare Professionals: Reflecting on Clinical Practice. Radcliffe Pub.; 2011. 162 p.

19. Ledford CJW, Seehusen DA, Canzona MR, Cafferty LA. Using a teaching OSCE to prompt learners to engage with patients who talk about religion and/or spirituality. Acad Med. 2014 Jan;89(1):60-5.

20. Pietkiewicz I, Smith J. A practical guide to using Interpretative Phenomenological Analysis in qualitative research psychology. CPPJ. 2014 Jan 1;20:7-14.
21. Taylor EJ. Spiritual Care: Nursing Theory, Research, and Practice. Prentice-Hall; 2002. 324 p.

22. Gibbs G. Learning by Doing: A Guide to Teaching and Learning Methods. FEU; 1988. $129 \mathrm{p}$.

23. Driessen E, Tartwijk J van, Dornan T. The self critical doctor: helping students become more reflective. BMJ. 2008 Apr 10;336(7648):827-30.

24. Mann K, Gordon J, MacLeod A. Reflection and reflective practice in health professions education: a systematic review. Adv Health Sci Educ Theory Pract. 2009 Oct;14(4):595-621.

25. Ayala GX, Elder JP. Qualitative methods to ensure acceptability of behavioral and social interventions to the target population. J Public Health Dent. 2011;71(0 1):S69-79.

26. Aronson L. Twelve tips for teaching reflection at all levels of medical education. Med Teach. 2011;33(3):200-5.

27. Sandars J. The use of reflection in medical education: AMEE Guide No. 44. Med Teach. 2009 Aug;31(8):685-95.

28. Vivekananda-Schmidt P, Marshall M, Stark P, Mckendree J, Sandars J, Smithson S. Lessons from medical students' perceptions of learning reflective skills: A multi-institutional study. Medical Teacher. 2011 Oct 1;33(10):846-50.

29. Swanwick T, Forrest K, O'Brien BC. Understanding Medical Education: Evidence, Theory, and Practice. second. John Wiley \& Sons; 2014. 602 p.

30. Tanaka M, Okamoto R, Koide K. Relationship between Reflective Practice Skills and Volume of Writing in a Reflective Journal. Health. 2018 Mar 14;10(3):283-8.

31. Soodmand Afshar H, Farahani M. Reflective Thinking and Reflective Teaching among Iranian EFL Teachers: Do Gender and Teaching Experience Make a Difference? Procedia - Social and Behavioral Sciences. 2015 Jun 1;192:615-20.

32. Aronson L, Niehaus B, Lindow J, Robertson PA, O'sullivan PS. Development and pilot testing of a reflective learning guide for medical education. Medical Teacher. 2011 Oct 1;33(10):e515-21. 
33. Sukhato K, Sumrithe S, Wongrathanandha C, Hathirat S, Leelapattana W, Dellow A. To be or not to be a facilitator of reflective learning for medical students? a case study of medical teachers' perceptions of introducing a reflective writing exercise to an undergraduate curriculum. BMC Med Educ. 2016 Apr 4;16:102.

34. Lailiana NA, Handayani A. Motivasi Berprestasi Ditinjau Dari Komitmen Terhadap Tugas Pada Mahasiswa. Proceedings Education and Language International Conference [Internet]. 2017 Jun 7 [cited 2020 Apr 23];1(1). Available from: http://jurnal.unissula.ac.id/index.php/ ELIC/article/view/1228

35. Shahabuddin Hashim, Mahani Razali, Ramlah Jantan. Psikologi pendidikan. Kuala Lumpur: PTS Professional Pub.; 2006.

36. Hojat M, Gonnella JS, Mangione S, Nasca TJ, Veloski JJ, Erdmann JB, et al. Empathy in medical students as related to academic performance, clinical competence and gender. Medical Education. 2002;36(6):522-7.
37. Stanley S, Bhuvaneswari GM. Reflective ability, empathy, and emotional intelligence in undergraduate social work students: a cross-sectional study from India. Social Work Education. 2016 Jul 3;35(5):560-75.

38. Irfani TH, Gunawan J, Tosepu R, Nuru H. Experiences of being co-assistant: a pilot study. International Journal of Research in Medical Sciences. 2017 Jan 14;3(10):2580-3.

39. MacLean CD, Susi B, Phifer N, Schultz L, Bynum D, Franco M, et al. Patient Preference for Physician Discussion and Practice of Spirituality. J Gen Intern Med. 2003 Jan;18(1):38-43.

40. Wen LS, Baca JT, O’Malley P, Bhatia K, Peak D, Takayesu JK. Implementation of smallgroup reflection rounds at an emergency medicine residency program. CJEM. 2013 May;15(3):175-7. 